\title{
Assessment of facial asymmetry and establishment of threshold of sub-clinical asymmetry in Malwa population
}

\author{
Dr Chandni Bharti,' Dr Sandhya Jain, ${ }^{2}$ Dr Harsh Vibhor Bharti3 \\ 'Asst Prof, Dept of Orthodontics, People's college of dental sciences \& research center, Bhopal (M.P.) India, \\ 2Prof \& HOD, Dept of Orthodontics, Government College of Dentistry, Indore (M.P.) India \\ ${ }^{3}$ Asst Prof, Rishiraj college of Dentistry, Bhopal(M.P.) India
}

Correspondence: Dr Chandni Bharti; Email: drchandnibharti@gmail.com

\section{ABSTRACT}

Introduction: The word symmetry is derived from the Greek word 'symmetries' which means 'of like measure'. Facial symmetry can be defined in numerous ways, one being associated with the state of facial equilibrium, in which there is a correspondence in size, shape, and arrangement of facial landmarks on the opposite sides.

Materials \& Method: The 1427 subjects in the present study were selected from the Out Patient Department of Government College of Dentistry, Indore(M.P), who presented with aesthetically pleasing faces over a period of one year (October 2013-October 2014). Out of the 1427 patients examined 150 (17-30 years) subjects were randomly included. Photographs and orthopantomogram of all the 150 patients were obtained.

Result: The photographs and orthopantomogram were analyzed \& Absolute value of Asymmetry Index was taken for all the measurements. Comparison of absolute Asymmetry index of different parameters between male and female subjects was performed. Wilcoxon paired test showed right side predominance for the parameter corpus length, middle facial width, cheek length, lower facial width.

Conclusion: In the present study an attempt was made to quantify sub-clinical asymmetries in clinically symmetrical faces. Minor asymmetries were observed in nearly all individuals taken up for the study. There is no association of gender with predominance of facial asymmetry. On assessment of side predominance of asymmetry it was concluded that the right side dominance of asymmetry for corpus length, middle facial width, cheek length, lower facial width. A threshold value of $6 \%$ for sub-clinical asymmetry was established from this study except for condylar and coronoid.

Keywords: Asymmetry index, Facial asymmetry, Photographic analysis

\section{INTRODUCTION\}

The word symmetry is derived from the Greek word 'symmetria' which means 'of like measure'. Facial symmetry can be defined in many different ways. It is most commonly associated with the state of facial equilibrium, in which there is correspondence in size, shape, and arrangement of facial landmarks on the opposite sides of the median sagittal plane. ${ }^{1.2}$ Perfect bilateral symmetry is largely a theoretical concept. ${ }^{3}$

Human beings like any other creation of god display bilateral symmetry except for some minor negligible variations. By strict definition, this implies that mirror image mathematical identity exists between right and left halves. Because of biological imperfection, some of which are inherent in the developmental process and some of which is caused by environmental disturbance, such asymmetry is rarely encountered. Therefore, asymmetry within reasonable bounds cannot be considered as an abnormal condition. However, what is considered to be within reasonable bounds is largely the result of subjective opinion, because accepted objective standards do not exist by which a judgment of abnormality can be made.

The subject of symmetry or lack of symmetry of the human face is of considerable interest, particularly in the field of orthodontics. There is no visible demarcation line, or even a range, marking the distinction between normal and abnormal asymmetry in terms of soft tissue characteristics. A demarcation line which can be determined by subjective evaluation such as of the patient's, or the orthodontist's perception of the facial asymmetry.

Soft tissue features are quantified by measuring frontal facial photographs, and the relationship of these measurements with cephalometric measurements has been reported. ${ }^{4}$ There have only been few studies 
on the correlation between the perception of facial asymmetry and the panoramic measurements; and no reports of the establishing relationship between the perception of facial asymmetry, soft tissue measurements using the same photographs and orthopantomographic measurements. Till date and to the best of our knowledge, no study of this nature, wherein varied objective parameters(i.e. dental, skeletal and esthetic parameters) were compared by objective measure in India and in the district of Indore, Madhya Pradesh. The aim of the study is to survey the facial frontal photographs by subjectively evaluating facial asymmetry with a questionnaire and to determine the differences in soft tissue measurements between the individuals selected from Malwa population having esthetically pleasing profile.

The next step is to determine soft tissue characteristics of patients, having underlying sub-clinical asymmetry, in a well balance group of subjects visiting Government College of Dentistry, Indore (M.P.) and were recognized subjectively for qualities of facial esthetics including symmetry along with determining a borderline/ threshold, beyond which patient can be considered to possess asymmetry which may help clinician to make a differential diagnosis of asymmetric patients and develop an appropriate treatment plan, along with evaluating side predominance of mandibular asymmetry.

\section{MATERIALS AND METHOD}

The 1427 subjects in the present study were selected from the Out Patient Department of Government College of Dentistry, Indore (M.P.) with aesthetically pleasing faces over a period of one year(October 2013-October 2014). Out of the 1427 patients examined 100 (17-30 years) subjects were randomly included havingclinically harmonious and symmetrical face, full complement of dentition except third molar, Angle's Class I Molar relationship with minimum crowding $(<4$ $\mathrm{mm}$ ), no functional deviation (CR CO discrepancy) and having good posterior inter-digitations.Each patient selected for the study was explained about the studyand each patient signed written consent form.Ethical committee of Government College of Dentistry, Indore (M.P.), gave the ethical clearance of the present study. Patient's having Angle's Class II \& III malocclusion; patient undergoing orthodontic treatment, anterior /posterior cross bite, moderate severe crowing, and supernumerary teeth, patient with any history of trauma, craniofacial congenital diseases and tempero-mandibular disorder etc. were excluded from the study.

Photographic procedure: The photographs were standardized being taken by a single operator who were unaware whether patients were included or not in the study. The photographic setup consisted

LANDMARKS \& PLANES USED FOR PHOTOGRAPHIC ANALYSIS ${ }^{5}$ (Figure 1,2)

\begin{tabular}{|l|l|l|}
\hline \multicolumn{1}{|c|}{ LANDMARK } & \multicolumn{1}{c|}{ DEFINITION } \\
\hline 'N' & Soft tissue nasion & The point in the middle line located at thenasal root \\
\hline 'Ga' & Soft tissue glabella & The most anterior point of the middleline of the forehead \\
\hline 'Sn' & Soft tissue sub-nasale & Midpoint at the union of the lowerborder of the nasal septum andthe upper lip \\
\hline 'Pog' & Soft tissue pogonion & Soft tissue mid-point of the chin \\
\hline 'MCr' & Right eye medial canthus & Point on right medial canthus of eye \\
\hline 'LCl' & Left eye lateral canthus & Point on left medial canthus of eye \\
\hline 'LCr' & Right eye lateral canthus & Point on right lateral canthus of the eye \\
\hline 'MCl' & Left eye medial canthus & Point on left lateral canthus of the eye \\
\hline 'Pr' & Right pupil & Mid-point of the right pupil \\
\hline 'PI' & Left pupil & Mid-point of the left pupil \\
\hline 'Cr' & Right labial commissure & Mid-point of right side of the corner of mouth \\
\hline 'Cl' & Left labial commissure & Mid-point of left side of the corner of mouth \\
\hline 'TRr' & Right tragus & The most posterior point of the auricular tragus on right side \\
\hline 'TR I' & Left tragus & The most posterior point of the auricular Tragus on left side \\
\hline 'CHr' & Right cheek & Most prominent point of the lateral surface of the right cheek \\
\hline 'CHI' & Left cheek & Most prominent point of the lateral surface of the left cheek \\
\hline PLANES & \multicolumn{2}{|l|}{} \\
\hline Mid saggital reference plane(MSR) & Ga-Sn-Pog & Plane connecting soft tissue glabella-subnasale -pogonion \\
\hline Inter-pupillary plane & Pr-Pl perpendicular to MSR & Plane perpendicular to MSR plane connecting right and left pupil \\
\hline
\end{tabular}




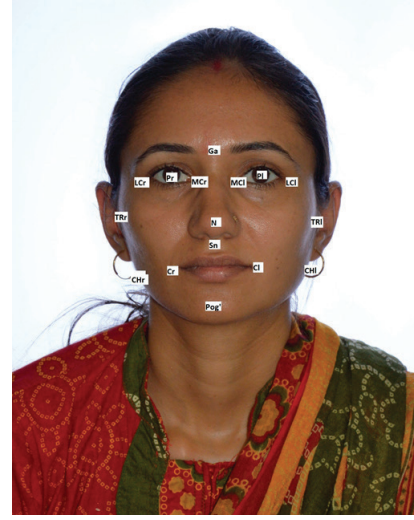

Figure 1: Landmarks and marks used in photographic analysis

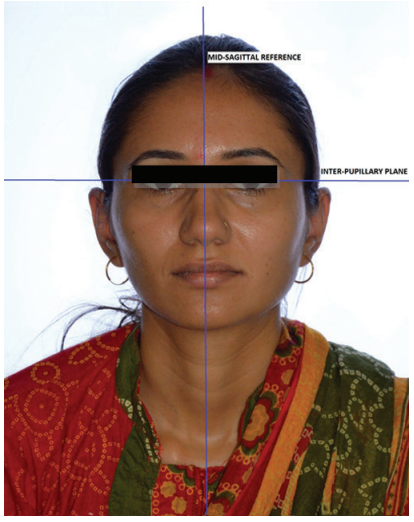

Figure 2: Planes in photographic analysis of a tripod stand that held Nikon D 3200 camera with a $55-105 \mathrm{~mm}$ macro lens and a primary flash. The photographs were taken from a fixed distance of 1.5 meter, from the patient; $30 \mathrm{~cm}$ from the lit box wooden stool was placed so that the patient can sit straight with his/her toes just behind a line drawn on the floor, looking straight at the camera with horizontal visual axis and remain expressionless. The stability of the elements and the easy adjustment of the tripod height allowed us to keep the optical axis of the lens horizontal during the recording. Patients were explained about the photographic procedure and were given identical instructions like tying back hair to allow visualization of the inferior ear insertions, removal of large earrings and glasses, so that the patient's forehead, neck, and ears were clearly visible during the recording. The photograph was printed with the same colored printer Konica Minolta Biz hub C224e using A4 size royal executive bond paper(thickness $85 \mathrm{gsm}$ ) to ensure that the photographs was identical throughout the study. OHP sheet was fixed on the printed photograph and vertical and horizontal reference line and landmarks were marked, vertical and horizontal measurements were measured and noted.

These photographs were subjected to scrutiny before a panel comprising of a lay observer, an orthodontist and a general practitioner for subjective evaluation of asymmetryscored ' 0 ' and ' 1 ' on the basis of prepared questionnaire, 60 patients were selected. OPG of the selected subjects was obtained and analyzed for percentage and severity of clinical asymmetry. The subjects were further divided into 'True symmetrical' (score 0) comprising of 27 subjects and 'symmetrical' (scored 1) comprising of 33 subjects.

Orthopantomogram procedure: The entire OPG procedure was explained to the subject prior to the

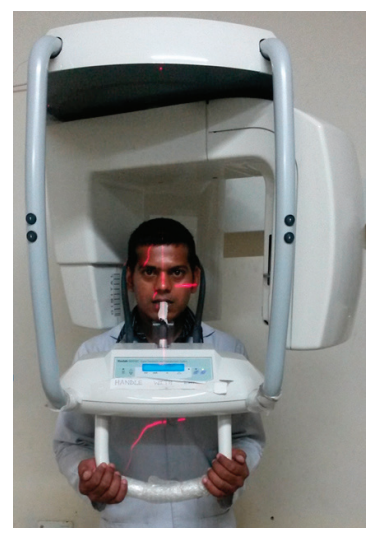

Figure 3: Standardization for orthopantomograph

procedure, so that the subject may not move from his/ her position after placement. The patient was asked to stand straight or sit erect in OPG machine; such that the patient's Frankfurt horizontal plane lies parallel to the floor and chin of the subject was placed on the chin rest. The subject was asked to place the tongue in such a way that it touches the palate. The subject was asked to bite on the bite block such that he/she may not be too far forward or backward. Any prosthesis, Jewelry, etc. was asked to be removed before the procedure. (Figure 3)

Orthopantomograms were taken by using same machine Carestream CS8000c (formerly Kodak K8000c). Obtaining digital OPG from single machine by a single operator did Orthopantomograph standardization.

After obtaining the OPG from the machine, it was assessed for any errors, only those panoramic radiographs presenting no artifacts, the whole mandible fully captured on the radiographs, and the contrast on the radiographs sufficient to perform all intended measurements were chosen.If any errors were found, the procedure was repeated. Mandibular first molar mesio- distal dimension was checked on both sides to look for any magnification. If present, such radiographs were eliminated.

OPG of all individuals will be analyzed for vertical measurement of condylar process, coronoid process, ramus, body/ corpus length, orbit to mesio-buccal cusp tip of maxillary molar on the right and left side.

The distortionthat occurs in a panoramic radiograph6 on the linear dimensions of the mandible on both sides, a distortion factor for each half of the mandible was calculated. For this, 10 radiographs from the sample 
LANDMARKS\& PLANES TO BE USED FOR OPG ANALYSIS (Figure 4,5)

\begin{tabular}{|c|c|c|c|}
\hline LANDMARK USED & LANDMARK & & DEFINITION \\
\hline Orbital & Or & Lowest point on b & sony orbit \\
\hline Anterior Nasal Spine & ANS & Tip of bony anteri & ior nasal spine \\
\hline Condylion & Co & Most superior poir & nt on head of mandibular condyle \\
\hline Coronoid point & Cor & Most superior poir & nt on the coronoid process \\
\hline Sigmoid notch point & Sig & Deepest point on & sigmoid/ mandibular notch \\
\hline Gonion & Go & Most postero-infer & rior point at the angle of mandible \\
\hline Mandibular midpoint & $\mathrm{Me}$ & $\begin{array}{l}\text { Located by proje } \\
\text { vertical plane. }\end{array}$ & cting the mental spine on the lower mandibular border parallel to ANS \\
\hline \multicolumn{4}{|l|}{ PLANES } \\
\hline Orbital plane & \multicolumn{2}{|l|}{ Or-Or } & Plane connecting bilateral points of the bony orbit \\
\hline Sigmod plane & \multicolumn{2}{|l|}{ Sig-Sig } & $\begin{array}{l}\text { Plane drawn parallel tothe orbital plane through deepest point on } \\
\text { sigmoid/ mandibular notch }\end{array}$ \\
\hline Middle saggital plane & \multicolumn{2}{|c|}{$\begin{array}{l}\text { Perpendicular to ANS from } \\
\text { orbital plane }\end{array}$} & $\begin{array}{l}\text { Line drawn perpendicular to orbital plane through the anterior nasal } \\
\text { spine(ANS) }\end{array}$ \\
\hline
\end{tabular}

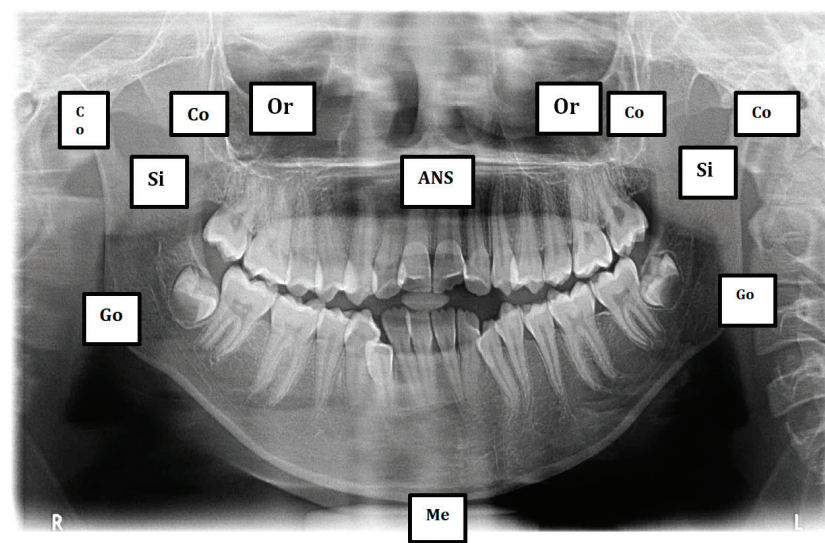

Figure 4: Landmarks used in orthopantomograph

were randomly selected and the study model obtained from the subjects was used to make comparisons. The mesio-distal dimensions (also the occluso-gingival height) of the four permanent molars were measured on the study models. The same distance will be then measured on the panoramic radiographs. The "distortion factor" was calculated by:Mesio-distal length of the cast (four first permanent molars) divided by mesio-distal length of the molars on the radiographs multiplied by 100. This distortion factor is mainly applied to mesio-distal measurements taken for the study like corpus length but not for vertical measurements.

The magnification factor was assessed with the use of two plus shaped metal wire, fixed to both sides of a dry skull on the body and ramus of the mandible. The magnification or distortion factorsfor right and left sides, which show no asymmetric enlargement or asymmetric shortening of bilateral wire markers. A single operator manually traced OPG radiographswith use of 0.75 microns lacquered polyester, acetate tracing paper fixed on the radiograph using a $0.35 \mathrm{~mm}$ lead pencil. Asymmetry will be drawn for all four measurements.

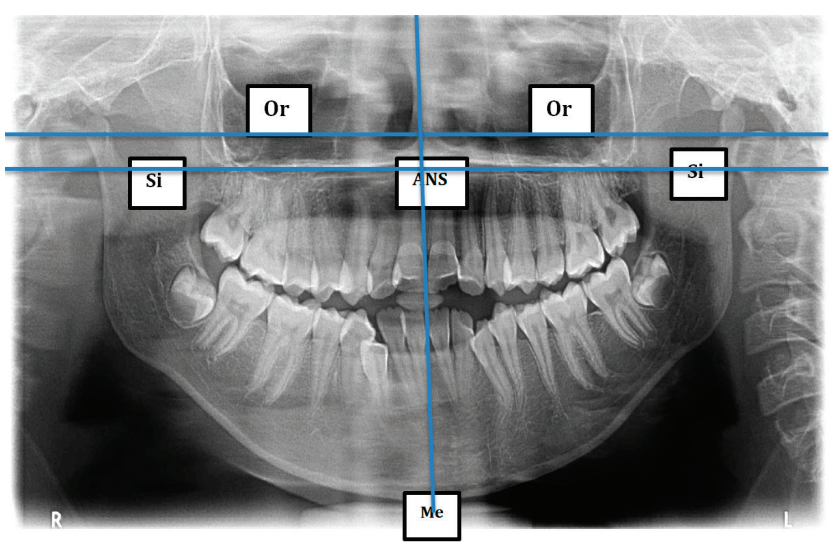

Figure 5: Planes to be used for for OPG analysis

ASYMMETRY INDEX $=\frac{\text { Right }- \text { left measurement }}{\text { Right }+ \text { left measurement }} \times 100 \%$

The index was calculated following the formula proposed by Habets $(1987)^{7}$ and Saglam and Shanti $(2003)^{8}$

\section{RESULT}

The photographs and OPG were analyzed \& Absolute value of Asymmetry Index was taken for all the measurements. Microsoft Excel (Redmond, Washington, USA) was used to compile the data. The data collected was analyzed using SPSS 18 (SPSS, Chicago, Illinois, USA). Alpha error was set at 0.05 and a 'p' value 0.05 was considered statistically significant.

Descriptive statistics (Mean, Minimum, Maximum, Stand. Deviation) was calculated for total 60 samples, 30 female 30 male samples separately (Table 1). The t-Test was used to compare the mean values of parameters between males and females. The result of t-test showed statistically insignificant differences between males and female subjects except for the mean right and left TRH, Gonial Angle, Middle facial width and facial height 
Table 1: Comparison of mean of different parameters between male and female subjects ( $\dagger$ Test)

\begin{tabular}{|c|c|c|c|c|c|c|c|c|c|c|c|c|c|c|c|}
\hline \multirow{3}{*}{ SN } & \multirow{3}{*}{ Parameters } & \multirow{2}{*}{\multicolumn{2}{|c|}{$\begin{array}{c}\text { Right } \\
(\mathrm{N}=60)\end{array}$}} & \multirow{2}{*}{\multicolumn{2}{|c|}{$\begin{array}{c}\text { Left } \\
(\mathrm{N}=60)\end{array}$}} & \multicolumn{4}{|c|}{ Right } & \multirow{3}{*}{$\begin{array}{c}p- \\
\text { Value }\end{array}$} & \multicolumn{4}{|c|}{ Left } & \multirow{3}{*}{$\begin{array}{c}p- \\
\text { value }\end{array}$} \\
\hline & & & & & & \multicolumn{2}{|c|}{ Male $(n=30)$} & \multicolumn{2}{|c|}{ Female $(n=30)$} & & \multicolumn{2}{|c|}{ Male $(n=30)$} & \multicolumn{2}{|c|}{ Female $(n=30)$} & \\
\hline & & $\begin{array}{c}\text { Mean ( } \\
\mathrm{mm})\end{array}$ & $\begin{array}{c}\text { SD } \\
(\mathrm{mm})\end{array}$ & $\begin{array}{l}\text { Mean } \\
(\mathrm{mm})\end{array}$ & $\begin{array}{c}\text { SD } \\
(\mathrm{mm})\end{array}$ & $\begin{array}{l}\text { Mean } \\
(\mathrm{mm})\end{array}$ & $\begin{array}{c}\text { SD } \\
(\mathrm{mm})\end{array}$ & $\begin{array}{l}\text { Mean } \\
(\mathrm{mm})\end{array}$ & $\begin{array}{c}\text { SD } \\
(\mathrm{mm})\end{array}$ & & $\begin{array}{l}\text { Mean } \\
(\mathrm{mm})\end{array}$ & $\begin{array}{c}\text { SD } \\
(\mathrm{mm})\end{array}$ & $\begin{array}{l}\text { Mean } \\
(\mathrm{mm})\end{array}$ & $\begin{array}{c}\text { SD } \\
(\mathrm{mm})\end{array}$ & \\
\hline 1 & Total Ramal Height & 66.075 & 6.08 & 65.25 & 5.64 & 69.11 & 6.32 & 63.03 & 4.04 & $0.00 *$ & 68.13 & 5.86 & 62.38 & 3.65 & $0.00 *$ \\
\hline 2 & Condylar Height & 8.55 & 2.66 & 9.00 & 2.44 & 8.60 & 2.88 & 8.50 & 2.47 & 0.886 & 9.08 & 2.31 & 8.91 & 2.61 & 0.79 \\
\hline 3 & Coronoid Height & 12.33 & 3.04 & 12.09 & 2.89 & 12.66 & 3.26 & 12.50 & 2.86 & 0.676 & 11.81 & 3.22 & 12.36 & 2.54 & 0.46 \\
\hline 4 & 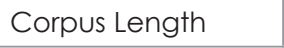 & (10.1 & 8.12 & 179.12 & 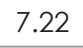 & 3.05 & 1.98 & .00 & 7.78 & 0.913 & 61 & 0.71 & 3 & 7.56 & .60 \\
\hline 5 & Gonial Angle & 116.16 & 5.45 & 116.19 & 5.13 & 114.70 & 6.09 & 117.63 & 4.43 & $0.036^{*}$ & 114.88 & 5.37 & 117.49 & 4.60 & $0.04^{*}$ \\
\hline 6 & Orbit To 6 & 48.02 & 2.95 & 47.88 & 3.21 & 48.36 & 3.05 & 47.68 & 2.86 & 0.375 & 48.10 & 3.52 & 47.66 & 2.91 & 0.60 \\
\hline 7 & Middle Facial Width & 47.59 & 3.57 & 45.90 & 3.49 & 46.50 & 3.96 & 48.68 & 2.80 & $0.017^{*}$ & 44.50 & 3.43 & 47.31 & 2.99 & $0.001^{*}$ \\
\hline .8 & Lower Facial Width & 40.41 & 3.45 & 38.48 & 2.93 & 40.31 & 3.40 & 40.51 & 3.55 & 0.825 & 37.98 & 2.76 & 38.98 & 3.05 & 0.18 \\
\hline 9 & Cheek Length & 34.39 & 3.90 & 34.93 & 4.22 & 33.86 & 4.23 & 34.91 & 3.55 & 0.302 & 34.43 & 4.83 & 35.43 & 3.52 & 0.36 \\
\hline 10 & Facial Height & 44.99 & 3.06 & 45.20 & 3.03 & 44.18 & 2.45 & 45.80 & 3.41 & $0.04^{*}$ & 44.33 & 2.364 & 46.07 & 3.41 & $0.02^{*}$ \\
\hline
\end{tabular}

Table 2: Comparison of absolute Asymmetry index of different parameters between male and female subjects ( $t$ Test)

\begin{tabular}{|c|c|c|c|c|c|c|c|c|}
\hline \multirow[t]{2}{*}{ SN } & \multirow[t]{2}{*}{ Parameters } & \multicolumn{2}{|c|}{$\begin{array}{l}\text { Total sample } \\
\qquad(\mathrm{N}=60)\end{array}$} & \multicolumn{2}{|c|}{$\begin{array}{l}\text { Male subjects } \\
\quad(n=30)\end{array}$} & \multicolumn{2}{|c|}{$\begin{array}{l}\text { Female subjects } \\
\qquad(n=30)\end{array}$} & \multirow[t]{2}{*}{$\mathrm{p}$-Value } \\
\hline & & Mean & SD & Mean & SD & Mean & SD & \\
\hline 1 & Al of total ramal height & 1.97 & 1.43 & 1.91 & 1.62 & 2.03 & 1.23 & 0.75 \\
\hline 2 & Al of condylar height & 9.86 & 8.00 & 11.67 & 8.40 & 8.04 & 7.26 & 0.07 \\
\hline 3 & Al of coronoid height & 10.62 & 8.79 & 13.67 & 10.54 & 7.57 & 5.16 & $0.006^{*}$ \\
\hline 4 & Al of corpus length & 2.98 & 2.27 & 3.05 & 1.984 & 2.91 & 2.55 & 0.81 \\
\hline 5 & Al of gonial angle & 2.62 & 2.83 & 3.01 & 3.56 & 2.23 & 1.83 & 0.29 \\
\hline 6 & Al of orbit to 6 & 1.53 & 1.36 & 1.73 & 1.65 & 1.32 & 1.00 & 0.25 \\
\hline 7 & Al of middle facial width & 2.83 & 2.37 & 2.99 & 2.58 & 2.67 & 2.17 & 0.60 \\
\hline 8 & Al of lower facial width & 3.35 & 2.62 & 3.68 & 3.16 & 3.37 & 1.99 & 0.65 \\
\hline 9 & Al of cheek length & 1.86 & 1.70 & 2.11 & 2.07 & 1.60 & 1.22 & 0.24 \\
\hline 10 & Al of facial height & 0.91 & 1.00 & 0.81 & 0.67 & 1.02 & 1.24 & 0.42 \\
\hline
\end{tabular}

On comparison of absolute Asymmetry index(Al) of different parameters between male and female subjects (Table 2) it was derived that there was no statically significant difference in male and female subjects regarding to asymmetry index derived from most of the parameters except mean of Al Coronoid height $(P=0.006)$ for male and female.

Based on the Al value of each parameter the subject was classified as left, right predominance or symmetrical. The Chi-square test was used to see association of gender with predominance. No association was found between the gender and predominance. (Table 3)

Wilcoxon paired test (Table 4) showed right side predominance for the parameter corpus length, middle facial width, cheek length, lower facial width. (Figure 6) On the basis of severity of Asymmetry Index, high percentage of subject showed very mild-to-mild asymmetry with respect to total ramal height, orbit to 6, Gonial angle and corpus length while a high percentage of subjects showed moderate to severe asymmetry with respect to condyle and coronoid height.

On assessment of $95 \%$ Confidence interval value highest value of $\mathrm{Al}$ in OPG was observed in coronoid

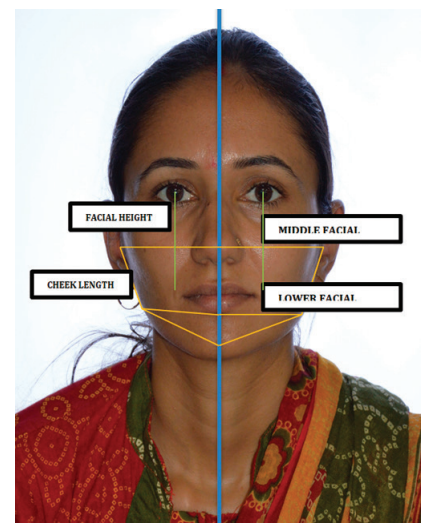

Figure 6: Measurements to be performed on the photograph 
Table 3: Predominance of the facial Asymmetry index (Al) in male and female subjects (Chi square test)

\begin{tabular}{|c|c|c|c|c|c|c|c|c|c|c|c|}
\hline & & \multicolumn{3}{|c|}{$\begin{array}{l}\text { Male Subjects } \\
\qquad(n=30)\end{array}$} & \multicolumn{3}{|c|}{$\begin{array}{l}\text { Female Subjects } \\
\qquad(n=30)\end{array}$} & \multirow{2}{*}{$\begin{array}{l}\text { Chi square value } \\
\text { (2-sided test) }\end{array}$} & \multicolumn{3}{|c|}{$\begin{array}{l}\text { Total Sample } \\
(N=60)\end{array}$} \\
\hline & & L & $s$ & $\mathbf{R}$ & L & $s$ & $\mathbf{R}$ & & L & $S$ & $\mathbf{R}$ \\
\hline \multirow{2}{*}{ Total Ramal height } & $n$ & 11 & 1 & 18 & 13 & 2 & 15 & \multirow{2}{*}{0.68} & 24 & 3 & 33 \\
\hline & $\%$ & $36.7 \%$ & $3.3 \%$ & $60 \%$ & $43.3 \%$ & $6.7 \%$ & $50 \%$ & & $40 \%$ & $5 \%$ & $5 \%$ \\
\hline \multirow{2}{*}{ Condylar height } & $n$ & 17 & 2 & 11 & 14 & 1 & 15 & \multirow{2}{*}{0.53} & 31 & 3 & 26 \\
\hline & $\%$ & $56.7 \%$ & $6.7 \%$ & $36.7 \%$ & $46.7 \%$ & $3.3 \%$ & $50 \%$ & & $51.7 \%$ & $5 \%$ & $43.3 \%$ \\
\hline \multirow{2}{*}{ Coronoid height } & $n$ & 11 & 1 & 18 & 18 & 1 & 11 & \multirow{2}{*}{0.18} & 29 & 2 & 29 \\
\hline & $\%$ & $36.7 \%$ & $3.3 \%$ & $60 \%$ & $60 \%$ & $3.3 \%$ & $36.7 \%$ & & $48.3 \%$ & $3.3 \%$ & $48.3 \%$ \\
\hline \multirow{2}{*}{ Corpus length } & $n$ & 7 & 2 & 21 & 6 & 0 & 24 & \multirow{2}{*}{0.32} & 13 & 2 & 45 \\
\hline & $\%$ & $23.3 \%$ & $6.7 \%$ & $70 \%$ & $20 \%$ & $0 \%$ & $80 \%$ & & $21.7 \%$ & $3.3 \%$ & $75 \%$ \\
\hline \multirow{2}{*}{ Orbit to 6} & $n$ & 14 & 2 & 14 & 14 & 4 & 12 & \multirow{2}{*}{0.66} & 28 & 6 & 26 \\
\hline & $\%$ & $46.7 \%$ & $6.7 \%$ & $46.7 \%$ & $46.7 \%$ & $13.3 \%$ & $40 \%$ & & $46.7 \%$ & $10 \%$ & $43.3 \%$ \\
\hline \multirow{2}{*}{ Go angle difference } & $n$ & 8 & 7 & 15 & 15 & 3 & 12 & \multirow{2}{*}{0.149} & 23 & 10 & 27 \\
\hline & $\%$ & $26.7 \%$ & $23.3 \%$ & $50 \%$ & $50.0 \%$ & $10.0 \%$ & $40.0 \%$ & & $38.3 \%$ & $16.7 \%$ & $45.0 \%$ \\
\hline \multirow{2}{*}{ Middle facial width } & $n$ & 5 & 3 & 22 & 5 & 1 & 24 & \multirow{2}{*}{0.58} & 10 & 4 & 46 \\
\hline & $\%$ & $16.7 \%$ & $10.0 \%$ & $73.3 \%$ & $16.7 \%$ & $3.3 \%$ & $80.0 \%$ & & $16.7 \%$ & $6.7 \%$ & $76.7 \%$ \\
\hline \multirow{2}{*}{ Lower facial width } & $n$ & 9 & 1 & 20 & 6 & 1 & 23 & \multirow{2}{*}{0.667} & 15 & 2 & 43 \\
\hline & $\%$ & $30.0 \%$ & $3.3 \%$ & $66.7 \%$ & $20.0 \%$ & $3.3 \%$ & $76.7 \%$ & & $25.0 \%$ & $3.3 \%$ & $71.7 \%$ \\
\hline \multirow{2}{*}{ Cheek length } & $n$ & 19 & 4 & 7 & 14 & 4 & 12 & \multirow{2}{*}{0.35} & 33 & 8 & 19 \\
\hline & $\%$ & $63.3 \%$ & $13.3 \%$ & $23.3 \%$ & $46.7 \%$ & $13.3 \%$ & $40.0 \%$ & & $55.0 \%$ & $13.3 \%$ & $31.7 \%$ \\
\hline \multirow{2}{*}{ Facial height } & $n$ & 13 & 7 & 10 & 10 & 7 & 13 & \multirow{2}{*}{0.67} & 23 & 14 & 23 \\
\hline & $\%$ & $43.3 \%$ & $23.3 \%$ & $33.3 \%$ & $33.3 \%$ & $23.3 \%$ & $43.3 \%$ & & $38.3 \%$ & $23.3 \%$ & $38.3 \%$ \\
\hline
\end{tabular}

Table 4: Comparison of means of different parameters on the right and left side (Wilcoxon signed rank Test)

\begin{tabular}{|c|c|c|c|c|c|c|c|}
\hline & $\mathbf{N}$ & Mean & S.D. & Minimum & Maximum & Z & Asymp. Sig. (2-tailed) \\
\hline RightTotal ramal height (Co-Go mm) & 60 & 66.07 & 6.08 & 58.00 & 81.00 & \multirow{2}{*}{$-1.894 a$} & \multirow{2}{*}{.058} \\
\hline Left Total ramal height(Co-Go mm) & 60 & 65.25 & 5.64 & 56.00 & 78.50 & & \\
\hline Right Condylar height(Co-tangent) & 60 & 8.55 & 2.66 & 3.50 & 16.50 & \multirow{2}{*}{$-1.478 b$} & \multirow{2}{*}{.140} \\
\hline Left Condylar height(Co-tangent) & 60 & 9.00 & 2.44 & 4.00 & 18.00 & & \\
\hline $\begin{array}{l}\text { Right Coronoid height(Cor-sigmoid } \\
\text { plane) }\end{array}$ & 60 & 12.33 & 3.04 & 6.00 & 18.50 & \multirow{2}{*}{$-.481 a$} & \multirow{2}{*}{.630} \\
\hline $\begin{array}{l}\text { Left Coronoid height(Cor-sigmoid } \\
\text { plane) }\end{array}$ & 60 & 12.09 & 2.89 & 5.00 & 19.00 & & \\
\hline Right Corpus length(Go-Me) & 60 & 103.11 & 8.12 & 86.00 & 117.00 & \multirow{2}{*}{$-4.155 a$} & \multirow{2}{*}{.000} \\
\hline Left Corpus length(Go-Me) & 60 & 99.12 & 7.22 & 82.00 & 117.50 & & \\
\hline Right Go angle & 60 & 116.16 & 5.45 & 104.50 & 132.00 & \multirow{2}{*}{$-.585 b$} & \multirow{2}{*}{.559} \\
\hline Left Go angle & 60 & 116.19 & 5.13 & 104.50 & 128.50 & & \\
\hline Right Orbit to 6 & 60 & 48.02 & 2.95 & 42.00 & 53.00 & \multirow{2}{*}{$-.316 a$} & \multirow{2}{*}{0.75} \\
\hline Left Orbit to 6 & 60 & 47.88 & 3.21 & 42.00 & 54.50 & & \\
\hline Right Middle facial width & 60 & 47.59 & 3.57 & 37.00 & 56.50 & \multirow{2}{*}{$-4.106 a$} & \multirow{2}{*}{.000} \\
\hline Left Middle facial width & 60 & 45.90 & 3.49 & 36.00 & 54.00 & & \\
\hline Right Cheek length & 60 & 34.39 & 3.90 & 26.50 & 43.50 & \multirow{2}{*}{$-2.345 b$} & \multirow{2}{*}{.019} \\
\hline Left Cheek length & 60 & 34.93 & 4.22 & 26.00 & 46.00 & & \\
\hline Right Lower facial width & 60 & 40.41 & 3.45 & 33.50 & 48.00 & \multirow{2}{*}{$-4.217 a$} & \multirow{2}{*}{.000} \\
\hline Left Lower facial width & 60 & 38.48 & 2.93 & 33.00 & 48.00 & & \\
\hline Right Facial height & 60 & 44.99 & 3.062 & 39.00 & 52.00 & \multirow{2}{*}{$-1.039 b$} & \multirow{2}{*}{.299} \\
\hline Left Facial height & 60 & 45.20 & 3.039 & 39.00 & 51.00 & & \\
\hline
\end{tabular}


Table 5: Percentage of severity of mandibular asymmetry for different parameters (Al/Degree)

\begin{tabular}{|c|c|c|c|c|c|c|}
\hline S.No & Measurement & & Non Significant (0-2.99\%) & Mild(3-5\%) & Moderate(5 $\geq 10 \%)$ & Severe( $>10 \%)$ \\
\hline \multirow{2}{*}{1} & \multirow{2}{*}{ Al of Total Ramal height } & $n$ & 45 & 12 & 3 & 0 \\
\hline & & $\%$ & $75 \%$ & $20 \%$ & $5 \%$ & $0 \%$ \\
\hline \multirow{2}{*}{2} & \multirow{2}{*}{$\begin{array}{l}\text { Al of Condylar height } \\
\text { (Co- Tangent) }\end{array}$} & $\mathrm{n}$ & 8 & 8 & 22 & 22 \\
\hline & & $\%$ & $13.3 \%$ & $13.3 \%$ & $36.6 \%$ & $36.6 \%$ \\
\hline \multirow{2}{*}{3} & \multirow{2}{*}{$\begin{array}{l}\text { Al of Coronoid height } \\
\text { (cor- sigmoid plane) }\end{array}$} & $\mathrm{n}$ & 7 & 12 & 15 & 26 \\
\hline & & $\%$ & $11.6 \%$ & $20 \%$ & $25 \%$ & $43.3 \%$ \\
\hline \multirow{2}{*}{4} & \multirow{2}{*}{$\begin{array}{l}\text { Al of Corpus length } \\
\text { (Go-Me) }\end{array}$} & $\mathrm{n}$ & 33 & 16 & 11 & 0 \\
\hline & & $\%$ & $55 \%$ & $26.6 \%$ & $18.3 \%$ & $0 \%$ \\
\hline \multirow{2}{*}{5} & \multirow{2}{*}{ Al of Orbit -6} & $n$ & 50 & 9 & 1 & 0 \\
\hline & & $\%$ & $83.3 \%$ & $15 \%$ & $1.7 \%$ & $0 \%$ \\
\hline \multirow{2}{*}{6} & \multirow{2}{*}{$\begin{array}{l}\text { Al of Gonial angle } \\
\text { (degree) }\end{array}$} & $\mathrm{n}$ & 37 & 19 & 4 & 0 \\
\hline & & $\%$ & $61.6 \%$ & $31.6 \%$ & $6.7 \%$ & $0 \%$ \\
\hline \multirow{2}{*}{7} & \multirow{2}{*}{ Al of Middle facial width } & $n$ & 39 & 11 & 10 & 0 \\
\hline & & $\%$ & $45 \%$ & $18.3 \%$ & $16.7 \%$ & $0 \%$ \\
\hline \multirow{2}{*}{8} & \multirow{2}{*}{ Al of cheek length } & $n$ & 50 & 8 & 1 & 1 \\
\hline & & $\%$ & $83.3 \%$ & $13.3 \%$ & $1.7 \%$ & $1.7 \%$ \\
\hline \multirow{2}{*}{9} & \multirow{2}{*}{ Al of Lower facial width } & $n$ & 32 & 11 & 16 & 1 \\
\hline & & $\%$ & $53.3 \%$ & $18.3 \%$ & $26.6 \%$ & $1.7 \%$ \\
\hline \multirow{2}{*}{10} & \multirow{2}{*}{ Al of Facial height } & $n$ & 59 & 0 & 1 & 0 \\
\hline & & $\%$ & $98.3 \%$ & $0 \%$ & $1.7 \%$ & $0 \%$ \\
\hline
\end{tabular}

height(14.94) and lowest value in Gonial angle (0.71) and orbit to 6 region (0.32) while among photographic parameters highest value was observed in Lower facial width (3.60) and lowest value in facial height(0.38) showing less asymmetry in maxillary region than in mandibular region (Table 6).

Among all selected OPG parameters, the maximum percentage of asymmetry out of total number of sample was found in condylar region and coronoid $88.3 \%$ and $86.6 \%$ respectively likewise the percentage of asymmetry was $45 \%$ in corpus length, $38.3 \%$ in Go angle, $25 \%$ in total ramal height and least percentage of asymmetry was found in Orbit to 6 parameter 16.7.Among all selected photographic parameters maximum percentage of asymmetry was found in lower facial width $46.6 \%$, middle facial width showed $35 \%$,cheek length $16.7 \%$, and least percentage asymmetry in facial height $1.7 \%$.

On the basis of severity of asymmetry at $95 \%$ confidence interval, all parameters showed very mild-to-mild asymmetry (3-5\%) except coronoid and condylar height, which showed moderate to severe degree of asymmetry between right and left side in symmetrical faces.
In Figure 7 when Al of True symmetry group ( $\mathrm{n}=27)$, symmetry group $(n=33)$ and total number of subjects $(\mathrm{N}=60)$ was plotted for each parameter it was found that $6 \%$ was the threshold of underlying subclinical facial asymmetry.

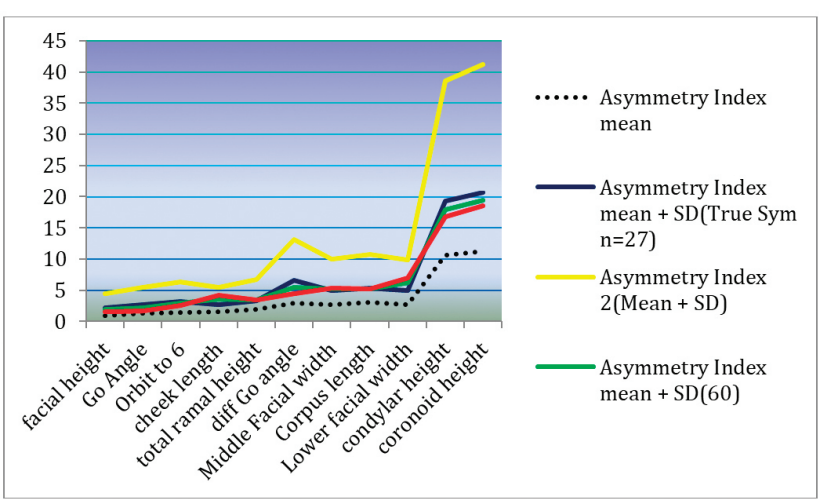

Figure 7: A diagrammatic chart to classify the degree of asymmetry on the basis of Asymmetry Index in aesthetically pleasing faces. A red line indicates the mean asymmetry index plus the standard deviation of symmetrical group $(n=33)$. A blue line indicates the mean asymmetry index plus the standard deviation of True symmetrical group ( $n=27)$. A green line indicated the mean asymmetry index plus the standard deviation of total sample $(\mathrm{N}=60)$. Another line (yellow) indicates twice the baseline values. The dotted black line indicates the mean asymmetry indexes of all samples taken in the study. 
Table 6: Descriptive statistics of Al for different parameters in True symmetrical and symmetrical faces

\begin{tabular}{|c|c|c|c|c|c|c|c|c|c|c|}
\hline & & $\mathbf{N}$ & Mean & S.D. & Std. Error & $\begin{array}{r}95 \% \mathrm{C} \\
\text { In }\end{array}$ & $\begin{array}{l}\text { fidence } \\
\text { val }\end{array}$ & Minimum & $\begin{array}{l}\text { Maxi- } \\
\text { mum }\end{array}$ & $t$ test \\
\hline \multirow{3}{*}{$\begin{array}{l}\text { Absolute Al Total ramal } \\
\text { height(Co-Go) }\end{array}$} & True Symmetrical & 27 & 1.91 & 1.42 & 0.27 & 1.35 & 2.48 & .00 & 5.46 & .772 \\
\hline & symmetrical & 33 & 2.02 & 1.47 & 0.26 & 1.50 & 2.54 & .00 & 6.25 & \\
\hline & Total & 60 & 1.97 & 1.43 & 0.19 & 1.60 & 2.34 & .00 & 6.25 & \\
\hline \multirow{3}{*}{$\begin{array}{l}\text { Absolute Al of Condy- } \\
\text { lar height(Co-tangent) }\end{array}$} & True Symmetrical & 27 & 10.61 & 8.69 & 1.67 & 7.18 & 14.05 & .00 & 39.13 & .515 \\
\hline & symmetrical & 33 & 9.25 & 7.48 & 1.30 & 6.59 & 11.90 & .00 & 28.57 & \\
\hline & Total & 60 & 9.86 & 8.00 & 1.03 & 7.79 & 11.93 & .00 & 39.13 & \\
\hline \multirow{3}{*}{$\begin{array}{l}\text { Absolute Al Coronoid } \\
\text { height(Cor-sigmoid } \\
\text { plane) }\end{array}$} & True Symmetrical & 27 & 11.22 & 9.41 & 1.81 & 7.50 & 14.94 & 1.18 & 37.77 & .640 \\
\hline & symmetrical & 33 & 10.14 & 8.37 & 1.46 & 7.17 & 13.11 & .00 & 34.69 & \\
\hline & Total & 60 & 10.63 & 8.79 & 1.13 & 8.36 & 12.90 & .00 & 37.77 & \\
\hline \multirow{3}{*}{$\begin{array}{l}\text { Absolute Al Corpus } \\
\text { length(Go-Me) }\end{array}$} & True Symmetrical & 27 & 3.01 & 2.35 & 0.45 & 2.08 & 3.94 & .23 & 9.18 & .929 \\
\hline & symmetrical & 33 & 2.96 & 2.24 & 0.39 & 2.16 & 3.75 & .00 & 9.38 & \\
\hline & Total & 60 & 2.98 & 2.27 & 0.29 & 2.40 & 3.57 & .00 & 9.38 & \\
\hline \multirow{3}{*}{ Absolute Diff Go angle } & True Symmetrical & 27 & 3.00 & 3.56 & 0.68 & 1.60 & 4.41 & .00 & 18.00 & .356 \\
\hline & symmetrical & 33 & 2.32 & 2.08 & 0.36 & 1.58 & 3.06 & .00 & 8.00 & \\
\hline & Total & 60 & 2.63 & 2.84 & 0.37 & 1.89 & 3.36 & .00 & 18.00 & \\
\hline \multirow{3}{*}{ Absolute AI Go angle } & True Symmetrical & 27 & 1.29 & 1.46 & 0.28 & 0.71 & 1.87 & .00 & 7.31 & .214 \\
\hline & symmetrical & 33 & 0.92 & 0.78 & 0.14 & 0.64 & 1.19 & .00 & 3.50 & \\
\hline & Total & 60 & 1.08 & 1.14 & 0.15 & 0.79 & 1.38 & .00 & 7.31 & \\
\hline \multirow{3}{*}{ Absolute Al Orbit to 6} & True Symmetrical & 27 & 1.49 & 1.69 & 0.32 & 0.82 & 2.16 & .00 & 7.69 & .841 \\
\hline & symmetrical & 33 & 1.56 & 1.07 & 0.19 & 1.19 & 1.94 & .00 & 4.25 & \\
\hline & Total & 60 & 1.53 & 1.37 & 0.18 & 1.18 & 1.89 & .00 & 7.69 & \\
\hline \multirow{3}{*}{$\begin{array}{l}\text { Absolute Al Middle } \\
\text { facial width }\end{array}$} & True Symmetrical & 27 & 2.64 & 2.37 & 0.46 & 1.71 & 3.58 & .00 & 8.37 & .574 \\
\hline & symmetrical & 33 & 2.99 & 2.40 & 0.42 & 2.14 & 3.85 & .00 & 9.47 & \\
\hline & Total & 60 & 2.84 & 2.37 & 0.31 & 2.22 & 3.45 & .00 & 9.47 & \\
\hline \multirow{3}{*}{$\begin{array}{l}\text { Absolute Al Cheek } \\
\text { length }\end{array}$} & True Symmetrical & 27 & 1.52 & 1.20 & 0.23 & 1.05 & 1.99 & .00 & 4.58 & .165 \\
\hline & symmetrical & 33 & 2.14 & 2.01 & 0.35 & 1.43 & 2.85 & .00 & 10.17 & \\
\hline & Total & 60 & 1.86 & 1.71 & 0.22 & 1.42 & 2.30 & .00 & 10.17 & \\
\hline \multirow{3}{*}{$\begin{array}{l}\text { Absolute Al Lower } \\
\text { facial width }\end{array}$} & True Symmetrical & 27 & 2.72 & 2.23 & 0.43 & 1.83 & 3.60 & .00 & 9.21 & .029 \\
\hline & symmetrical & 33 & 4.19 & 2.77 & 0.48 & 3.21 & 5.17 & .00 & 12.04 & \\
\hline & Total & 60 & 3.53 & 2.63 & 0.34 & 2.85 & 4.21 & .00 & 12.04 & \\
\hline \multirow{3}{*}{$\begin{array}{l}\text { Absolute Al Facial } \\
\text { height }\end{array}$} & True Symmetrical & 27 & 0.89 & 1.31 & 0.25 & 0.38 & 1.41 & .00 & 6.66 & .883 \\
\hline & symmetrical & 33 & 0.93 & 0.68 & 0.12 & 0.69 & 1.17 & .00 & 2.38 & \\
\hline & Total & 60 & 0.92 & 1.00 & 0.13 & 0.66 & 1.17 & .00 & 6.66 & \\
\hline
\end{tabular}

\section{DISCUSSION}

Facial asymmetry is frequently occurring in individuals, the so- called symmetrical faces represent a combination of numerous, minor-asymmetrical components. ${ }^{9}$

In the present study Al was used to quantify facial asymmetry because $\mathrm{Al}$ is much better than measuring linear differences due to magnification occurring in OPG between right and left side. Measuring Al is easy and effective for calculating asymmetry and is not affected by positioning errors, distortion and magnification. ${ }^{10}$

OPG is a reliable tool for determining mandibular asymmetry. ${ }^{7,8,10-21}$ It was used to assess $\mathrm{Al}$ because it offers a method to analyze the various structures of mandible separately on the right and left side. 7,13,14,20,21 Acceptable results can be achieved with OPG, which is non-invasive, have a favorable cost-benefit relationship and exposure of subjects to relatively low doses of radiation. ${ }^{17}$

Reproducibility of vertical and angular measurements on OPG is acceptable if the patient's head is positioned 
properly in the equipment. ${ }^{13,14,22}$ Habets et $a^{7,20,21}$ concluded that the head holder must be fixed well to the orthopantomograph, and the head has to be well centered in the head holder of the orthopantomograph when a clinical orthopantomograph is to be evaluated.

The method used for standardization in this study was easy to use and reproducible in any clinical setting and also does not require the use of any setup of accessory lighting equipment.

The findings of this study conclude that most of the parameter show that mild to moderate skeletal asymmetries exist in otherwise clinically symmetric patients confirming previous studies ${ }^{1,2,25}$ except instudies on PA Cephalogram by Goel, Ambedkar et al $2003^{34}$ and Rajpara et al in $2014^{35}$ which concluded that asymmetries are common findings in otherwise normal looking faces and more than $50 \%$ of the examined patients $(N=50)$ in their study showed asymmetry of 2 $\mathrm{mm}$ or more in the cranial region. 3-D photographic study by Bugaighis et al in $2011^{36}$ on aesthetically pleasing Caucasian children concluded that some amount of asymmetry is present in aesthetically pleasing faces.

Descriptive statistics (mean, minimum, maximum, SD) were calculated for total 60 samples, i.e. 30 male and 30 female samples separately. The result of t-Test showed statistically insignificant differences between males and females (Table 1). Results were similar to study by Ramirez et al $2010^{6}$ on OPG which took two similar parameters (ramus height and corpus length). Similar study was performed by Ahmed et al $2011^{27}$ on OPG by taking different parameters who also stated that the degree of asymmetry of face was independent of gender. Study on Lateral Oblique radiograph by Duthie et al $2007^{28}$ (body length, ramus height and gonial angle) also showed similar results by taking different parameters. Another study by Azevedo et al $2006^{29}$, Kurt, Uysal et al $2008^{30}$ on Class II subdivision on Submentovertex and PA cephalogram showed similar results by taking different parameters. Study by Haraguchi et al $2008^{31}$ on PA cephalogram also found similar results.

Ferrario et al in $1993^{5}$ on photographic evaluation found that cheek length was higher in male than in female subjects. But in 2001 another study by him on 3-dimensional photographs concluded similar results i.e no significant difference in asymmetry between male and females. Study by Aksu et al in $2010^{33}$ also showed dissimilar results with respect to Lower facial width. Bugaighis et al in $2011^{26}$ performed 3-D photographic study on aesthetically pleasing Caucasian children concluded that statistically significant difference with respect to middle facial width which showed higher value in males then in females and no statistically significant difference with respect to facial height. Study by $G$. Kranthipraveen raj et al $2014^{33}$ on frontal photograph of aesthetically pleasing profile showed dissimilar results by taking different landmarks in which males have higher Lower facial width and middle facial width than in females. The reason for dissimilar results could be because of selected subjects was of different facial types and racial differences.

The results indicate that more than a half of the population $(\mathrm{N}=60)$ studied had a considerable difference in dimensions between the two sides of the mandible unaffected whether the individual is male or female.

Similarly there was no statically significant difference in male and female subjects regarding to asymmetry index derived from all the parameters (Table 2) Omer Said Sezgin (2007) ${ }^{34}$ performed similar type of study on OPG but on different types of malocclusion group and found no significant mean asymmetry values between male and female samples. Results are similar to another study by kurt, Uysal et al $2008^{30}$ on OPG but in their study samples were unilateral, bilateral crossbite and normal occlusion group.

Based on Asymmetry Index each parameter was classified left, right predominance or symmetrical. Chi square test was used to check association of gender with predominance. No association was found between the gender and predominance (Table 3).

Wilcoxon paired test showed right side predominace for the parameters corpus length, middle facial width, lower facial width except for cheek length which showed left side predominance (Table 4). The findings were similar to study done by Shah \& Joshi (1978),' Peck \& Peck $1991^{2}$ and Melnik(1992), ${ }^{35}$ they alsofound right side predominance in their respective studies but they used Postero-anterior cephalogram to determine asymmetry using different parameters. The results are dissimilar to study by Ramirez et al $2010^{6}$ who found left side predominance with respect to corpus length and ramus height. The reason could be because of 
the difference in the method of measurement and landmark selection on OPG. Rajpara et al $2014^{25}$ performed PA cephalogram study on aesthetically pleasing faces concluded right predominance with respect to Total ramal height (Co-Go length) and left predominance with respect to corpus length (Co-Me length).

Another study by Ahmad et al in $2011^{27}$ on asymmetry in clinically symmetrical faces with skeletal Class I and Class III by OPG found left side predominance by taking different measurements. Similarly Vig and Hewitt (1975) ${ }^{23}$ also found left side dominance but on PA cephalogram. Only few studies are available till date which investigated angular asymmetries in the craniofacial complex. Our study found no statistically significant difference in gonial angle measured between the sides. Study by Kwon et al., 2006 ${ }^{36}$ Kurt et al., $2008^{30}$ showed similar results. But study by Ramirez et al., 2010' has shown contrary results, there was a statistically significant difference between the right and left sides. The means showed that the left gonial angle was more open than right. Rajpara et al $2014^{25}$ performed PA cephalometric study on aesthetically pleasing faces concluded right predominance of gonial angle.

In all previous investigations a significant facial asymmetry has been demonstrated even in aesthetically pleasing faces but no agreement exist about the side of dominance.

On the basis of severity of Asymmetry Index, high percentage of subject showed very mild to mild asymmetry with respect to total ramal height, orbit to 6 , Gonial angle and corpus length while high percentage of subjects showed moderate to severe asymmetry with respect to condyle and coronoid height. (Table 5)

In the present study, ramal height showed insignificant asymmetry in contrast to study done by Ramirez et al $2010^{6}$ who showed moderate asymmetry. The difference could be because we selected subjects with aesthetically pleasing faces with asymmetry rating range from 0 to 1 while Ramirez selected growing individuals randomly and also differences were there in the method of measurements The present study shows similar results to study done by Ramirez et al who also found very mild asymmetry as far as Gonial angle is concerned.
In present study high percentage of subject showed very mild asymmetry of corpus length. The results were dissimilar to study done by Ramirez et al $2010^{6}$ in which high percentage of subjects showed moderate asymmetry. This could be due to difference in methods of measurement and because the present study took aesthetically pleasing rather symmetrical faces.

On assessment of $95 \%$ Confidence interval value highest value of Asymmetry Index in OPG was observed in coronoid height(14.94) and lowest value in Gonial angle (0.71) and orbit to 6 region (0.32) while among photographic parameters highest value was observed in Lower facial width (3.60) and lowest value in facial height ( 0.38) showing less asymmetry in maxillary region than in mandibular region (Table 6).

Among all selected OPG parameters selected, the maximum percentage of asymmetry out of total number of sample was found in condylar region and coronoid $88.3 \%$ and $86.6 \%$ respectively likewise the percentage of asymmetry was $45 \%$ in corpus length, $38.3 \%$ in Go angle, 25 \% in total ramal height and least percentage of asymmetry was found in Orbit to 6 parameter $16.7 \%$.Among all selected photographic parameters maximum percentage of asymmetry was found in lower facial width $46.6 \%$,middle facial width showed $35 \%$, cheek length $16.7 \%$, and least percentage asymmetry in facial height $1.7 \%$.

There is lack of scientific evidence to define a range of facial asymmetry that is aesthetically acceptable. So far, there have been only few studies which have attempted to scientifically established threshold for facial asymmetry (borderline asymmetry beyond which the face is considered to be asymmetrical). Farkas ${ }^{37}$ and Ferrario et al, $2001^{38}$ used the mean plus two standard deviation as the maximum normal asymmetry to supply a threshold value for the identification of asymmetry. On the other hand, Katsumata and her colleagues ${ }^{39,40}$ defined a point as asymmetric when the right and left difference was larger than the mean plus one standard deviation, and further defined it is marked asymmetry when the point demonstrated a value more than twice the mean plus one SD. On the basis of katsumata method the present study showed $6 \%$ as the threshold of underlying sub-clinical facial asymmetry (Figure 7). 
On the basis of severity of asymmetry at $95 \%$ confidence interval, all parameters showed very mild to mild asymmetry (3-5\%) except coronoid and condylar height which showed moderate to severe degree of asymmetry between right and left side in symmetrical faces (Table 6). Lu (1965) (11 $^{2}$ reported that only facial asymmetries greater than $3 \%$ are clinically discernible. It is likely that the decision of the threshold value is rather subjective according to investigators or clinicians, particularly in the subject of asymmetry. The reason for dissimilar results to our study could be because of selected subjects was having different facial form, age, racial origin, head orientation and methodology.

\section{CONCLUSION}

In the present study an attempt was made to quantify subclinical asymmetries in clinically symmetrical faces. Minor asymmetries were observed in nearly all individuals taken up for the study. There is no association of gender with predominance of facial asymmetry. On assessment of side predominance of asymmetry it was concluded that the right side dominance of asymmetry for corpus length, middle facial width, cheek length, lower facial width. A threshold value of $6 \%$ for sub-clinical asymmetry was established from this study except for condylar and coronoid. Present data can be used as baseline data for further research.

OJN

\section{REFERENCES}

1. Shah S.M. and Joshi M.R. An assessment of asymmetry in the normal craniofacial complex. Angle Orthodontist 1978; $48(2)$ : $141-148$.

2. Peck S, Peck L. Skeletal asymmetry in esthetically pleasing faces. Angle Orthod 1991; 61: 43-8.

3. Bishara SE, Burkey PS, Kharouf JG. Dental and facial asymmetries: a review. Angle Orthod. 1994; 64:89-98

4. Good S, Edler R, Wertheim D, Greenhill D. Comparison of radiographic and photographic measurements of mandibular asymmetry. Am J Orthop 2003;123(2): 167-74.

5. Ferrario VF, Sforza C, Miani A, Tartaglia G. Craniofacial morphometry by photographic evaluations. Am J Orthod Dentofacial Orthop. 1993; 103:327-337.

6. Ramirez-Yañez G. O., Allyson Stewart, Erin Franken and Kenia Campos. Prevalence of mandibular asymmetries in growing patients Eur J orthod $2010,1-7$

7. Habets L L, Bezuur J N, van Ooji C P, Hansson T L The orthopantomogram an aid in diagnosis of temporomandibular joint problems I. The factor of vertical magnification. Journal of Oral Rehabilitation $1987,14: 475-480$.

8. Sanğlam AM, Sanli G. Condylar asymmetry measurements in patients with Temperomandibular disorders.J Contemporary Dental Practice5;Aug 2004.

9. Jämsä T, Rönning $O$. The facial skeleton in children affected by rheumatoid arthritis- a roentgen-cephalometric study. Eur J Orthod 1985 7: 48-56.

10. Kjellberg H, Ekestubbe A, Kiliaridis S, Thilander B. Condylar height on panoramic radiographs. Acta Odontol Scand. 1994; 52:43-50.

11. Miller VJ, Bodner L. Temperomandibular joint dysfunction in children. Int J Pediatr Otorhinolaryngol 1997 Jan3; $38(3): 215-25$.

12. Joondeph D R 2000 Mysteries of asymmetries. American Journal of Orthodontics and Dentofacial Orthopedics 1 17: 577-579.

13. Larheim TA, Svanaes DB.Johannessen S. Reproducibilty of radiographs with the orthopantomograph5:tooth-length assessment. Oral surg Oral Med Oral Pathol 1984 Dec;58(6):736-41.

14. Larheim TA, Svanaes DB. Reproducibility of rotational panoramic radiography: mandibular linear dimensions and angles. Am J Orthod Dentofacial Orthop. 1986:90:45-51.

15. VJ, Zeltser R, Zeltser $\mathrm{CH}$, Yoeli Z. The condylar asymmetry-age relationship in determining myogenous or arthrogenous origin of pain in patients with temporomandibular disorders. J Oral Rehabil. 1996;23:392-394.

16. WS Laster, JB Ludlow, LJ Bailey and H Garland Hershey. Accuracy of measurements of mandibular anatomy in cone beam computed tomography Oral sugery, Oral medicine, Oral radiology and endodontics 2005.

17. Kambylafkas P E, Murdock E, Gilda E, Tallents R H, Kyrkanides S 2006 Validity of panoramic radiographs for measuring mandibular asymmetry. Angle Orthodontist 76: 388-393.

18. Kiki A, Kilic N, Oktay H. Condylar asymmetry in bilateral posterior crossbite patients. Angle Orthod. 2007;77:77-81

19. Sezgin O S, Celenk P, Arici S 2007 Mandibular asymmetry in different occlusion patterns. Angle Orthodontist 77: 803-807

20. Habets LL, Bezuur JN, Naeiji M, Hansson TL. The Orthopantomogram, an aid in diagnosis of temporomandibular joint problems. II. The vertical symmetry. J Oral Rehabil. 1988;15:465-471.

21. Habets LL, Bezuur JN, Jimene Lopez and Hansson T.L. the OPG: an aid in TMJ diagnostics. III. A comparision between lateral tomography and dental rotational radiography. J Oral Rehabil. 1989;15:401-406. 
22. Kiki A, Kilic N, Oktay H. Condylar asymmetry in bilateral posterior crossbite patients. Angle Orthod. 2007;77:77-81.

23. Vig P.S., Hewitt A.B. Asymmetry of the human facial skeleton. Angle Orthod 1975; 45: 125-129.

24. Goel S, Ambedkar A, Darda M, Sonar S. An assessment of facial asymmetry in Karnataka population. J of Indian orthodontic society 2003 36:30-8.

25. Yagnesh Rajpara, Tarulatha R. Shyagali, Kalyani Trivedi, Prabhuraj Kambalyal, Tapan Sha, Varun Jain Evaluation of facial asymmetry in esthetically pleasing facesJournal of Orthodontic Research | May-Aug 2014 | Vol 2 | Issue 2

26. Bugaighis I., Mattck C., Tidderman B., Hobson R. Three dimensional gender difference in facial form of children in the North East of England. European Journal of Orthdontics April 2011

27. Ahmed F. Aljarad, Hayder F. Saloom, Ali Ismail Al-Bustani. Facial dimensions and asymmetry in clinically symmetrical faces with skeletal Class I \& Class III malocclusion in an adult sample aged between 18-28 years (digital panoramic study). J Bagh Coll Dentistry 201 1; 23 (1):86-93).

28. Duthie J, Bharwani D, Tallents R H, Bellohusen R, Fishman L 2007 A longitudinal study of normal asymmetric mandibular growth and its relationship to skeletal maturation. American Journal of Orthodontics and Dentofacial Orthopedics 132: 179-184.

29. Azevedo A R, Janson G, Henriques J F, Freitas M R 2006 Evaluation of asymmetries between subjects with Class II subdivision and apparent facial asymmetry and those with normal occlusion. American Journal of Orthodontics and Dentofacial Orthopedics 129: 376-383.

30. Kurt G, Uysal T, Sisman Y, Ramoglu SI. Mandibular asymmetry in Class II subdivision malocclusion. Angle Orthod. 2008;78(1):32-7.

31. Seiji Haraguchi; Yoshitaka Iguchi; Kenji Takada.Asymmetry of the Face in Orthodontic PatientsAngle Orthodontist, Vol 78, No 3, 2008.

32. Aksu M, kaya D, Kocadereli I. Relability of reference distances used in photogrammetry .Angle orthod 2010;80:670-677.

33. G. Kranthipraveen Raj, Reddy Y.M, C. Sreekanth, Laxman Kumar and Vishnuvardhan Reddy Soft Tissue Analysis in Aesthetically Pleasing Profiles. Indian Journal of Mednodent and Allied Sciences Vol. 2, No. 2, June-July, 2014, pp- 155-160.

34. Sezgin O S, Celenk P, Arici S 2007 Mandibular asymmetry in different occlusion patterns. Angle Orthodontist 77: 803-807.

35. Melnik AK. A cephalometric study of mandibular asymmetry in a longitudinally followed sample of growing children. American Journal of orthodontics \& Dentofacial orthopaedics 1992;101:355-66.

36. Kwon T G, Park H S, Ryoo H M, Lee S H 2006 A comparison of craniofacial morphology in patients with and without facial asymmetry-a three-dimensional analysis with computed tomography. International Journal of Oral and Maxillofacial Surgery 35: $43-48$.

37. Farkas LG. Cheung Gwynne 'Facial asymmetry in healthy North American Caucasians' Angle orthod 1981; 51:76-78.

38. Ferrario VF, Sforza C,Ciusa V, Dellavia C, Tartaglia GM. The effect of sex and age on facial asymmetry $n$ healthy subjects:a cross-sectional study from adolescence to mid-adulthood. J Oral Maxillofac Surg 2001;59:382-8

39. Katsumata A, Fujishita M, Maeda M, Ariji Y, Ariji E, Langlais RP. 3D-CT evaluation of facial asymmetry. Oral Surg Oral Med Oral Pathol Oral Radiol Endod 2005;99:212-20

40. Maeda M, Katsumata A, Ariji Y, Muramatsu A, Yoshida K, Goto S, et al. 3D-CT evaluation of facial asymmetry in patients with maxillofacial deformities. Oral Surg Oral Med Oral Pathol Oral Radiol Endod 2006;102:382-90.

41. LU K H 1965 Harmonic analysis of the human face. Biometrics 21: 491-505. 